\title{
Standard Mandibular Canine Index of the Malaysian Indian student used for sex prediction in forensic dentistry
}

\author{
Beh Wee Ren, Rachman Ardan, Rasmi Rikmasari \\ Department of Forensic Dentistry/Prosthodontics Faculty of Dentistry Universitas Padjadjaran
}

\section{ABSTRACT}

Identification of the unknown body is a medical, legal and humane responsibility of the forensic team to evaluate data relevant to the identification. The purpose of this research was to obtain necessary data to compute and analyze the Mandibular Canine Index $(\mathrm{MCl})$ between Malaysian Indian males and females studying in Universitas Padjadjaran as well as to determine the Standard Mandibular Canine Index (Standard $\mathrm{MCl}$ ) for the Malaysian Indian community. This research used a descriptive and analytical survey approach and was done though a stratified random proportional sampling technique. The result of this research established a statistical significant difference between males and females Mandibular Canine Index $(\mathrm{MCl})$ with the level of confidence of $95 \%$ with the mean of males as $0.260 \pm 0.019$ and females as $0.236 \pm 0.012$. The Standard Mandibular Canine Index of the Malaysian Indian community was 0.248. The overall success to predict the sex using this Standard Mandibular Canine Index was $76.67 \%$. It was concluded that Standard Mandibular Canine Index could be used for sex prediction as a supporting technique.

Key words: Standard Mandibular Canine Index, sex prediction, sex determination, forensic dentistry, forensic odontology.

\section{INTRODUCTION}

As the earth ages, there are more and more natural disasters happening; as the human technology advances, more and more accidents are occurring; as the society modernized, the crime rate rapidly increases. In these cases, there are many unknown victims involved that needs

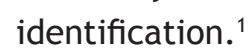

Identification of the unknown body is a medical, legal and humane responsibility of the forensic team to evaluate data relevant to the identification. ${ }^{2}$ First and foremost, the utmost important reason of identification is of a humane reason. Everyone who is born with an identity deserved the right to die with an identity. Secondly, it is essential to certify an individual as legally deceased before a death certificate can be filed. Identification of the remains may also provide the core for police investigation surrounding the circumstances of death and the corpus delicti for subsequent legal proceeding. ${ }^{2}$

Various method of identification has been employed in the establishment of unknown remains. Methods chose to identification depends on reliability of the method, availability of the antemortem data and postmortem condition of the remains. The least reliable methods are visual recognition and personal effects. The scientific methods include dactyloscopy (fingerprint rec- 
ognition), DNA comparison, medical conditions, skeletal characteristic, dental characteristic, and serology (blood test). Identification by exclusion has also been used with cross reference with other methods. ${ }^{2}$

Identification of the unknown body should be analyzed as a whole and must not be based simply upon one method especially if a least reliable method is used. ${ }^{3}$ Often the corroboration of the utilization of data gained from several of the less specific methods may elevate the probability of accurate identification. DNA comparison, dactyloscopy and dental methods are the most specific and hence, the most scientific method of identification applicable to the human body. ${ }^{2}$

Compared to DNA comparison and dactyloscopy, dental methods are relatively simple and require less expertise. Teeth and jaw is advantageous due to its individuality (uniqueness of dentition), durability and relative easy identification. It is possible to determine sex, race, age, status (class, power and financial), habits (oral hygiene, occupation, oral health consciousness), stature, profile, time of death and DNA composition through thorough analysis of the data obtained. ${ }^{2}$

Based upon previous researches, it is concluded that males generally have higher Mandibular Canine Index $(\mathrm{MCl})$ compared to females; the Standard Mandibular Canine Index (Standard $\mathrm{MCl}$ ) varies according to other influencing factors such as race, age, hereditary, growth and development. Thus a universal set of values will prove invalid. ${ }^{4}$

Mandibular Canine Index was the calculation of the average mesiodistal width of the mandibular canines divided by the intercanine space of mandibular canine where the mesiodistal width of mandibular canine was the measurement of the greatest width from the crest of curvature on the mesial surface (mesial contact point) to the crest of curvature on the distal surface (distal contact point) and the intercanine distance of mandibular canine was the measurement of displacement from the tip of the mandibular canines.

The researcher finds it particularly interesting that we are able to predict with certain confidence one's sex using dental method. The method chosen compares the Mandibular Canine Index $(\mathrm{MCl})$ from the subject with the Standard Mandibular Canine Index (Standard $\mathrm{MCl}$ ). Mandi- bular Canine Index $(\mathrm{MCl})$ is derived from the average mesiodistal width of both the mandibular canine divided by the mandibular intercanine distance while Standard Mandibular Canine Index (Standard $\mathrm{MCl}$ ) is the mean of the male and female Mandibular Canine Index. ${ }^{5}$

Amongst all teeth, the mandibular canines are found to exhibit greatest sexual dimorphism. ${ }^{6}$ According to Rao et al. ${ }^{5}$ Mandibular Canine Index $(\mathrm{MCl})$ is able to give a satisfactory result for sex determination. Muller et al. ${ }^{4}$ concluded that Rao, et al's. ${ }^{5}$ method can only be used in case of correct lower anterior dental alignment and by using the Standard Mandibular Canine Index (Standard MCl) of the local population.

The mandibular canines have an average age of eruption of 10.87 years and are less affected than any other teeth by periodontal diseases. These are the last teeth to be extracted. Canines are also better likely to survive severe trauma such as air disasters, hurricanes or conflagration. These findings indicate that mandibular canines may be considered as the 'key teeth' for personal identification. ${ }^{6}$

Garn et al. ${ }^{7}$ studied the magnitude of sexual dimorphism by measuring the mesiodistal width of the canine teeth of an Ohio Caucasian population and concluded that the magnitude of canine tooth sexual dimorphism varied among different local population. Local population mentioned by Muller et al. ${ }^{4}$ is more accurately replaced by ethnic group since variety ethnic groups influence the result of sex determination using Mandibular Canine Index. ${ }^{7}$

A parallel research was done involving North Indians was conducted to determine sex using Mandibular Canine Index. The researcher establishes the existence of a statistically significant sexual dimorphism in the morphometry of mandibular canines in North Indian population. ${ }^{6}$ A similar research was also done to acquire the Mandibular Canine Index involving the Indonesian students studying in Faculty of Dentistry, Universitas Padjadjaran.

This research has chosen to predict sex using Standard Mandibular Canine Index (Standard $\mathrm{MCl}$ ) in the Malaysian Indian student community studying in Padjadjaran University, Bandung. The researcher has to chosen the Malaysian Indian student community studying in Universitas 
Padjadjaran, Bandung due to the large population present in the university.

\section{MATERIALS AND METHODS}

This research took a descriptive and analytical approach of sampling. An initial pilot study was done to know the population size. The research was done though a stratified random proportional sampling technique that fulfills specific criteria. An impression to each sample of the population was taken to form a study model. All measurements were done extraorally upon the model. After calculation, data was analyzed using Student's t-distribution method to compare the difference of Mandibular Canine Index between Malaysian Indian student males and females. Lastly, Standard Mandibular Canine Index (Standard $\mathrm{MCl}$ ) was determined and used to predict the sex among the sample obtained in order to know the success rate of sex prediction using the index.

Locations of the research were at campus of Universitas Padjadjaran Jl. Raya Jatinangor $21^{\text {st }} \mathrm{km}$ Sumedang; Dr Hasan Sadikin General Hospital Jl. Pasteur 38 $8^{\text {th }}$ Bandung; and Oral and Dental Hospital, Faculty of Dentistry, Universitas Padjadjaran, Jl. Sekeloa Selatan 1, Bandung. The date of the research were carried out from $1^{\text {st }}$ February until $31^{\text {st }}$ April 2009.

The total number of the Malaysian Indian students studying in Universitas Padjadjaran was 216, with 76 male, and 140 female. The survey might fulfills the following population criteria, i.e.: Pure Indian at least 2 generation above; Age between 18 to 28 years old; Physically healthy with normal growth and development pattern; All anterior teeth of the mandible had fully erupted and might not be severely crowded or misaligned; didn't have any visible abnormality, disease, or other pathologic condition; didn't have any past or undergoing dental treatment including conservative, endodontic, prosthodontic, and orthodontic; and had a normal occlusion with normal overbite \& overjet and Angle's Class I molar relationship.

However due to time and financial restraint, a sample of 30 people was taken randomly to represent the population that fulfill all the criteria. This minimal sample was based upon the opinion of Gay and Diehl ${ }^{10}$ in an independent sample using t-test. In order for this research to unbiased, the number of sample of the males and females are taken proportionally making it 11 males and 19 females in proportion to the ratio of Malaysian Indian males and females that fulfill all the criteria.

Randomly taken Malaysian Indian students were approached to participate in this research and explained to them the purpose and procedures of this research. The subjects were then asked to fill up their personal data and sign a consent form to confirm their participation in this research. The subjects are seated in a slightly recline position on a dental chair with mouth opened and mandible parallel to the floor. A simple intraoral examination was done to confirm that the subject fulfills all the criteria stated thus suitable to participate in this research. If the subject fulfills all the criteria then the following procedures were carried out.

A suitable impression tray was selected and tried in the subject's mouth. The impression was taken to the patient and then poured. After setting, the cast material was removed from the impression material and examined for any deficiency. The cast material was added with a heptagon base to make a study model. The mesiodistal width of both mandibular canines was measured on the study model using a vernier caliper of scale $0.05 \mathrm{~mm}$ as shown in Figure 2 .

The alignment of the mandibular arch was corrected on the study model and the intercanine distance of the mandibular canine was measured using a vernier caliper. The alignment needs to be corrected in order to know the supposing intercanine distance. ${ }^{4}$ First, measure the mesiodistal width of all the mandibular anterior teeth and then superimposed the length starting from the midline for each side of the arch. The distal of the mandibular canine was assumed to end there. Then we measured the approximate cusp tip of the mandibular canine on the alignment of the dental arch. Thus a corrected intercanine distance was obtained as shown in Figure 3 and Figure 4. All measurements were repeated 3 times to obtain an average value. The data obtained was subjected to statistical analysis to derive conclusions.

First and foremost, the mean mesiodistal width of each mandibular canine was obtained by using the mean and standard deviation formula. Then the mean mesiodistal width of mandibular canine of each subject was obtained using the 


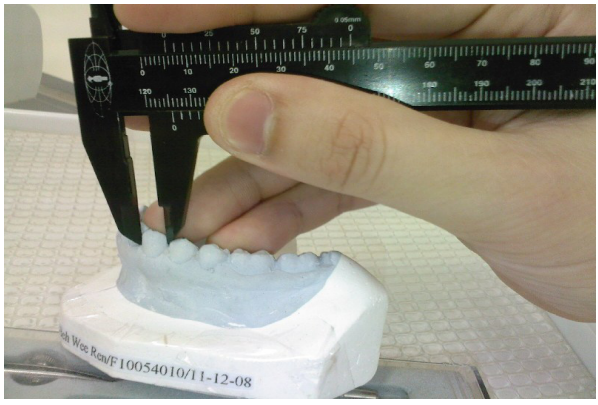

Figure 1. Measuring mesiodistal width of mandibular canine on study model.

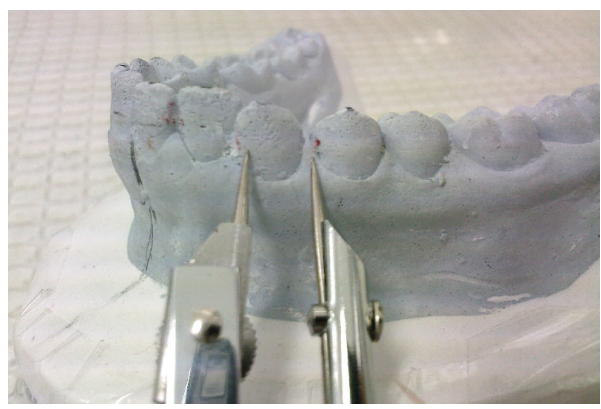

Figure 2. Correcting the mandibular arch alignment on the study model to measure corrected intercanine distance.

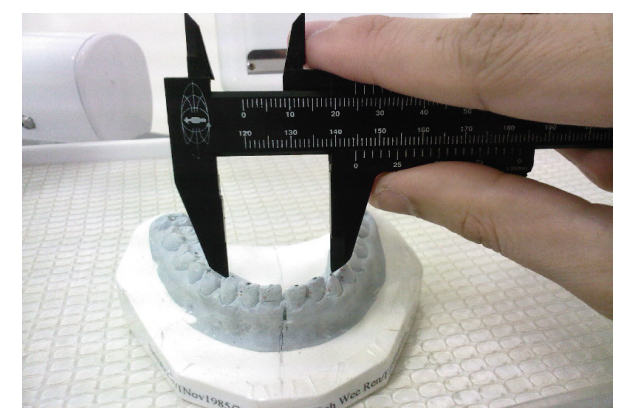

Figure 3. Measuring intercanine distance of mandibular canines on the study model.

combined mean and combined standard deviation formula. Using the same way, the mean mesiodistal width of mandibular canine of the Malaysian Indian students were obtained. Secondly, the mean intercanine distance and the mean intercanine distance of each subject was obtained using the mean and standard deviation formula.

The Mandibular Canine Index of each subject was obtained using the ratio of mean mesiodistal width of mandibular canine of each subject and mean intercanine distance of each subject. Then the mean Mandibular Canine Index were obtained using the mean and standard deviation formula, and then these mean Mandibular Canine Index were subjected to hypothesis testing using
Student's t-distribution. The Standard Mandibular Canine Index was obtained using the summation of the mean Mandibular Canine Index divided by 2 .

\section{RESULTS}

The mean mandibular canine mesiodistal width of the Malaysian Indian males and females studying in Universitas Padjadjaran were 7.07 \pm 0.25 $\mathrm{mm}$ and $6.31 \pm 0.37 \mathrm{~mm}$ respectively. Thus the mean mandibular canine mesiodistal width of males was bigger compared to females. The mean mandibular canine distance of the Malaysian Indian males and females were $27.13 \pm 2.11 \mathrm{~mm}$ and $26.59 \pm 1.48$ $\mathrm{mm}$ respectively. Thus the mean intercanine distance of males was bigger compared to females.

The Mandibular Canine Index $(\mathrm{MCl})$ of each Malaysian Indian students males and females were $0.260 \pm 0.019$ and $0.236 \pm 0.012$ respectively. Thus the mean Mandibular Canine Index (MCl) of Indian males was bigger than females. Based upon the mean Mandibular Canine Index ( $\mathrm{MCl}$ ) of Malaysian Indian males and females student, the value of the Standard Mandibular Canine Index (Standard $\mathrm{MCl}$ ) was obtained. The formula used is shown below:

Standard $\mathrm{MCl}=\frac{\text { Mean male } \mathrm{MCl}+\text { Mean female } \mathrm{MCl}}{2}$

0.248

Figure 4 shows the box plots of Mandibular Canine Index $(\mathrm{MCl})$. The mean Mandibular Canine Index $(\mathrm{MCl})$ for males was 0.26 while for females was 0.23 . It was observable that both the box plots have an overlap region from 0.23 to 0.25 called the critical region. There was also a secluded data of a female sample number 6 with Mandibular Canine Index $(\mathrm{MCl})$ of 0.27 . The variance of males seemed to bigger than females ranging from 0.23 to 0.29 while the females range from 0.22 to 0.25 .

\section{DISCUSSION}

In this research, the mean mandibular canine mesiodistal width of Malaysian Indian males and females studying in Universitas Padjadjaran were $7.07 \pm 0.25 \mathrm{~mm}$ and $6.31 \pm 0.37 \mathrm{~mm}$ respectively. In comparison to Kaushal et al. ${ }^{6}$ the mean mandibular canine mesiodistal width of North Indian males and females were $7.299 \pm 0.286 \mathrm{~mm}$ and $6.692 \pm 0.290 \mathrm{~mm}$. In the Indonesian popula- 


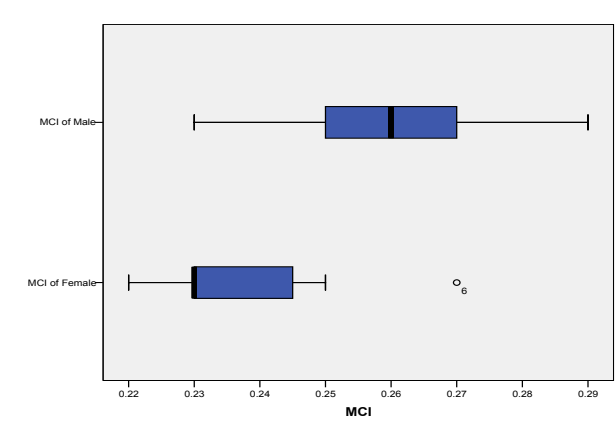

Figure 4. Box plots of Mandibular Canine Index (MCl) for Malaysian Indian males and females.

tion, the mean mandibular canine mesiodistal width of males and females were $7.200 \pm 0.070 \mathrm{~mm}$ and $6.770 \pm 0.058 \mathrm{~mm}$ respectively. ${ }^{8}$ This finding was consistent with other researcher stating that the mean mandibular canine mesiodistal width of males was generally bigger compared to females. However Al-Rifaiy et al. ${ }^{11}$ states that though the mean values mandibular canine widths were less for females than for males and the differences were not statistically significant in the Saudi Arabia population.

We also tabulated that the mean mandibular intercanine distance of Malaysian Indian males and females were $27.13 \pm 2.11 \mathrm{~mm}$ and $26.59 \pm 1.48 \mathrm{~mm}$ respectively. This was consistent with Kaushal et al's. ${ }^{12}$ findings as well with the mean mandibular intercanine distance of North Indian males and females were $25.873 \pm 1.253 \mathrm{~mm}$ and $25.070 \pm 1.197$ $\mathrm{mm}$ respectively. Other researcher such as Al-Rifaiy et al. ${ }^{11}$ also got the same conclusion that mean value for mandibular and maxillary intercanine distances for females were less than for males and the differences were statistically significant. Thus the mean intercanine distance of males was generally bigger compared to females.

The present study established the existence of a definite statistically significant sexual predilection pertaining to Mandibular Canine Index $(\mathrm{MCl})$ of the Malaysian Indian with the level of confidence as high as $95 \%$. The mean Mandibular Canine Index $(\mathrm{MCl})$ of Malaysian Indian males and females were $0.260 \pm 0.019$ and $0.236 \pm 0.012$ respectively. In other similar research, the mean Mandibular Canine Index $(\mathrm{MCl})$ of North Indian males and females were $0.281 \pm 0.012$ and $0.267 \pm 0.100$ respectively. ${ }^{6}$ Among Iranian men, the $\mathrm{MCl}$ ranged from 0.209 to 0.293 , with a mean of 0.252 . Among Iranian women, the $\mathrm{MCl}$ ranged from 0.202 to 0.276 , with a mean of 0.245 . There was significant statistical difference between the two means. ${ }^{7}$ This finding was consistent as it establishes that the mean Mandibular Canine Index $(\mathrm{MCl})$ of males was statistically bigger than females.

The value of the Standard Mandibular Canine Index (Standard $\mathrm{MCl}$ ) for the Malaysian Indian community was obtained as 0.248 . The Standard $\mathrm{MCl}$ for the North Indian community was 0.274 while the Standard $\mathrm{MCl}$ of the Iranian community was $0.247 .{ }^{6}$

Out of 11 males, 9 males had a Mandibular Canine Index greater than 0.248 . The success rate of this sex predilection was $81.81 \%$. Out of 19 females, we were able to predict 14 correctly. The success rate of this sex predilection was $73.68 \%$. Overall, we were able to predict the sex of 23 out of 30 people thus making the overall success to predict sex using this Standard Mandibular Canine Index to be as high as $76.67 \%$.

The rate of successful sex prediction for males and females were $81.81 \%$ and $73.68 \%$ respectively with an overall success to predict sex using this Standard Mandibular Canine Index (Standard $\mathrm{MCl}$ ) to be as high as $76.67 \%$. The percentage of cases correctly predicted in the North Indian population using the right Standard $\mathrm{MCl}$ of 0.273 were 70 and $80 \%$ respectively while the left Standard $\mathrm{MCl}$ of 0.275 were $66.67 \%$ and $83.33 \%$ respectively. ${ }^{6}$ The rate of correct classification of sex for Saudi Arabian population was $55.07 \%$ and $65.48 \%$, respectively. ${ }^{11}$

However, when the Mandibular Canine Index of the unknown body falls between the critical region between $0.23-0.25$. In this critical region, we were not able to predict sex accurately since there's an overlap of data. However, if the Mandibular Canine Index of the unknown body falls below the critical region we can be confident that the body is of a female and if the Mandibular Canine Index of the unknown body falls above the critical region we can be confident that the body is of a male.

In this research, we were able to achieve the purpose of the research that was to analyze the dental dimensions and sexual variation among the Malaysian Indian student community and to know whether was there a valid difference and predilection between the males and females By using the Standard Mandibular Canine Index 
(Standard $\mathrm{MCl}$ ) of 0.248 , we were also able to predict sex with certain confidence in Malaysian Indian population and achieve a high success rate.

This research offers a cheap, easy and fast way to predict sex in the Malaysian Indian population however this research was carried out with limited resources and financial aid. In order to achieve a higher accuracy and valid scientific as well as statistical evidence, a large sample was required. A more accurate method of measurement such as using digital instrument of measurement may also be incorporated to get a more satisfactory result. A more accurate result may also be obtained by increasing the significant digits and using computerized calculation.

The Indian race was divided mainly into the North Indians and South Indians. The North Indians are mainly originated from the Australoid race while the South Indians originated from the Mongoloid as well as the Caucasoid race. Comparing the results of the Standard Mandibular Canine Index (Standard $\mathrm{MCl}$ ) of this research and the North Indian, it is concluded that both data does not match. Thus this research may be inaccurate due to the mixture of races in the sample taken. In order to obtain a much more valid and accurate result, further research may be carried out based upon the racial classification. Another confounding variable to be considered was the age of the sample. It would be of definite advantage if further research may be able to consider the implication of age that affects the dimensions of tooth, especially those variables that were involved in this research.

Kaushal et al. ${ }^{6}$ further examined the differences of using right Mandibular Canine Index $(\mathrm{MCl})$ and left Mandibular Canine Index $(\mathrm{MCl})$ in predicting sex among the North Indian population. Though he found that there was no statistical difference in both the indexes in the North Indian population but that did not mean that it applies generally to every other race. Kaushal et al. ${ }^{6}$ also examined the difference between measuring the dental dimensions intraorally and extraorally and found that there were no statistical differences.

\section{CONCLUSION}

We were able to conclude that the mean mandibular canine mesiodistal width and mean corrected intercanine distance of males was big- ger compared to females. The mean Mandibular Canine Index $(\mathrm{MCl})$ of Malaysian Indian males was significantly bigger than females. The value of the Standard Mandibular Canine Index (Standard MCl) for the Malaysian Indian community was obtained as 0.248. Standard Mandibular Canine Index (Standard $\mathrm{MCl}$ ) could be used to predict sex and serves as a supplement for identification with confidence level of $95 \%$ with an overall success rate of as high as $76.67 \%$ in the Malaysian Indian student community.

\section{REFERENCES}

1. Keiser-Nielsen S. Person identification by means of the teeth. Bristol: Wright Production; 1980.

2. Sopher IM. Forensic dentistry. USA: Charles C. Thomas Publisher; 1976.

3. Clark DH. Practical forensic odontology. United Kingdom: Wright Publication; 1992.

4. Muller ML, Lupi-Peguriera G. Quatrehomme MB. Odontometrical method useful in determining gender and dental alignment. Forensic Sci Int 2001:121(1):194-7.

5. Rao NS, Rao NN, Pai ML, Kotain MS. 1989. Mandibular Canine Index-Aclue for establishing sexidentity. Forensic Sci Int 1989;42(1):249-54 .

6. Kaushal S, Patnaik VVG, Sood V, Agnihotri G. Sex determination in North Indians using Mandibular Canine Index. J Indian Acad Forensic Med 2004;26(2):45-9.

7. Akhlaghi M, Salavati M. Mandibulo-Canine Index value for sex identification. Tehran University Med J 2008;65(12):66-71.

8. Handayani RD. Perbedaan indeks mahkota klinis gigi kaninus rahang bawah antara lakilaki dengan perempuan pada mahasiswa FKG UNPAD untuk identifikasi jenis kelamin dalam odontologi forensik. Minor thesis. Bandung: Fakultas Kedokteran Gigi Universitas Padjadjaran.

9. Ghondosi A, Mosharraf R, Fadavi F. Sexual variation in bucco-lingual dimensions in Iranian dentition. Int J Dent Anthrop 12(1):1-7.

10. Gay LR, Diehl PL. Research methods for business and management. New York: Macmillan Publishing Co.; 1992. p. 126-41.

11. Al-Rifaiy MQ, Abdullah MA, Ashraf I, Khan N. Dimorphism of mandibular and maxillary canine teeth in establishing sex identity. The Saudi Dent J 2006;9(1):17. 